\title{
Comparative analysis of catfish BAC end sequences with the
} zebrafish genome

\author{
Hong Liu ${ }^{\dagger 1,2}$, Yanliang Jiang ${ }^{\dagger 1,3}$, Shaolin Wang1 ${ }^{1}$ Parichart Ninwichian ${ }^{1}$, \\ Benjaporn Somridhivej ${ }^{1}$, Peng $\mathrm{Xu}^{1}{ }^{1}$, Jason Abernathy ${ }^{1}$, Huseyin Kucuktas ${ }^{1}$ and \\ Zhanjiang Liu*1
}

\begin{abstract}
Address: ${ }^{1}$ The Fish Molecular Genetics and Biotechnology Laboratory, Department of Fisheries and Allied Aquacultures and Program of Cell and Molecular Biosciences, Aquatic Genomics Unit, Auburn University, Auburn, AL 36849, USA, ${ }^{2}$ College of Fisheries, Huazhong Agricultural University, Wuhan, 430070, China and ${ }^{3}$ Key Laboratory of Protein Chemistry and Developmental Biology of State Education Ministry of China, College of Life Sciences, Hunan Normal University, Changsha, 410081, China

Email: Hong Liu - lzh0003@auburn.edu; Yanliang Jiang - yzj0001@auburn.edu; Shaolin Wang - wangsha@auburn.edu; Parichart Ninwichian - ninwipa@auburn.edu; Benjaporn Somridhivej - arraor@yahoo.com; Peng Xu - xupeng77@gmail.com; Jason Abernathy - abernjw@auburn.edu; Huseyin Kucuktas - kucukhu@auburn.edu; Zhanjiang Liu* - zliu@acesag.auburn.edu

* Corresponding author †Equal contributors
\end{abstract}

Published: 10 December 2009

BMC Genomics 2009, 10:592 doi:10.1 186/|47|-2164-10-592
Received: 4 March 2009

Accepted: 10 December 2009

This article is available from: http://www.biomedcentral.com//47/-2/64//0/592

(C) 2009 Liu et al; licensee BioMed Central Ltd.

This is an Open Access article distributed under the terms of the Creative Commons Attribution License (http://creativecommons.org/licenses/by/2.0), which permits unrestricted use, distribution, and reproduction in any medium, provided the original work is properly cited.

\begin{abstract}
Background: Comparative mapping is a powerful tool to transfer genomic information from sequenced genomes to closely related species for which whole genome sequence data are not yet available. However, such an approach is still very limited in catfish, the most important aquaculture species in the United States. This project was initiated to generate additional BAC end sequences and demonstrate their applications in comparative mapping in catfish.

Results: We reported the generation of 43,000 BAC end sequences and their applications for comparative genome analysis in catfish. Using these and the additional 20,000 existing BAC end sequences as a resource along with linkage mapping and existing physical map, conserved syntenic regions were identified between the catfish and zebrafish genomes. A total of 10,943 catfish BAC end sequences $\left(17.3 \%\right.$ ) had significant BLAST hits to the zebrafish genome (cutoff value $\leq \mathrm{e}^{-5}$ ), of which 3,221 were unique gene hits, providing a platform for comparative mapping based on locations of these genes in catfish and zebrafish. Genetic linkage mapping of microsatellites associated with contigs allowed identification of large conserved genomic segments and construction of super scaffolds.

Conclusion: BAC end sequences and their associated polymorphic markers are great resources for comparative genome analysis in catfish. Highly conserved chromosomal regions were identified to exist between catfish and zebrafish. However, it appears that the level of conservation at local genomic regions are high while a high level of chromosomal shuffling and rearrangements exist between catfish and zebrafish genomes. Orthologous regions established through comparative analysis should facilitate both structural and functional genome analysis in catfish.
\end{abstract}




\section{Background}

Comparative mapping is a powerful tool to transfer genomic information from sequenced genomes to closely related species for which whole genome sequence data are not yet available. Such an approach was initially demonstrated by Fujiyama et al. [1] for the construction of the human-chimpanzee comparative map. In these closely related primate species, approximately $98 \%$ of chimpanzee BAC end sequences (BES) had significant BLAST hits to the human genome sequence allowing putative orthologues to be identified [1]. A similar approach was used for the construction of the human-mouse comparative map [2]. Subsequently, this approach was extensively used in mammals including construction of the humancattle, the human-horse, and the human-porcine comparative maps [3-5]. Most recently, this approach was utilized one step further for the construction of the comparative genome contig (CGC)-based physical map of the sheep genome [6], where CGC is established based on anchorage of the sheep BES onto the genome sequences of dog, cow, and human. These successes depended on high percentage of BLAST hits and/or high levels of genome collinearity.

Five teleost fish genomes have been fully sequenced http:/ Lwww.ensembl.org/index.html including zebrafish (Danio rerio, from the order of Cypriniformes), Japanese pufferfish (Fugu rubripes, from the order of Tetraodontiformes), green spotted pufferfish (Tetraodon nigroviridis, from the order of Tetraodontiformes), medaka (Oryzias latipes, from the order of Beloniformes), and three-spined stickleback (Gasterosteus aculeatus, from the order of Gasterosteiformes), while whole genome sequencing is also underway for tilapia http://www.cichidgenome.org; http/ www.broad.mit.edu/science/projects/mammals-mod els/ vertebrates-invertebrates/tilapia/tilapia-genome-sequencing-project. The availability of these whole genome sequences lends great opportunities for comparative genome analysis. Recently, major genomic resources have been developed from a number of fish species such as Atlantic salmon (Salmo salar) [7-9], rainbow trout (Oncorhynchus mykiss) [10,11], tilapia [12,13], gilthead sea bream (Sparus auratus) [14-17], European sea bass (Dicentrarchus labrax) [18,19], and channel catfish (Ictalurus punctatus) (for a review, see $[20,21]$ ).

Catfish is the major aquaculture species in the United States. It is one of the six species included in the U.S. National Animal Genome Project NRSP-8. A number of genome resources have been developed in catfish including a large number of molecular markers [22-25], genetic linkage maps [26-28], several hundred thousands of ESTs ([29-33]; Z. Liu, unpublished data), microarray platforms [34-38], BAC libraries [39,40], and BAC-based physical maps $[41,42]$. To enable BAC end sequence-based com- parative genome analysis, we previously reported generation of 20,366 BES in catfish [25]. In spite of the great value of those BES for the characterization of genome repeat structures [43] and for the identification of microsatellite markers, our previous comparative genome analysis using BES revealed very limited conservation between the catfish and zebrafish genomes. Of the 141 matepaired BES with genes on both ends of the BAC inserts, only $34(24.1 \%)$ were found in nearby genomic locations in the zebrafish genome, suggesting high levels of chromosomal rearrangements [40]. Such findings were in strong contrast to the situations found between medakasea bream, Tetraodon-sea bream, medaka-stickleback, Tetraodon-medaka, stickleback-sea bream, Tetraodon-stickleback genome comparisons where almost complete genome collinearities were found [44]. We speculated that our earlier inability to discover large extent of genome collinearity between catfish and zebrafish could be a result of the low numbers of BES and the lack of a physical map. Therefore, in this study, we extended our efforts in BAC end sequencing and generated additional 43,021 BES, bringing the total to 63,387 (25,676 mate-paired). Using these catfish BES and its BAC contig-based physical map [42], genetic linkage mapping of BAC end-anchored microsatellites, and the genome sequence of zebrafish, here we conducted extensive comparative genome analysis. We report the identification of conserved syntenies and demonstrate the construction of super scaffolds of contigs by genetic linkage mapping of BAC end-associated microsatellites.

\section{Results and Discussion \\ $B A C$ end sequencing}

As shown in Table 1, a total of 42,240 BAC inserts (6.13× clone-coverage of the channel catfish genome) were sequenced from both ends, resulting in 63,387 BES $\geq 200$ bp in length (75\% overall success rate), including 20,366 BES we previously reported [25]. Mate-paired BES were produced from 25,676 BAC clones, while only a single BES was obtained from 12,035 clones. The BES were of high quality as the Q20 length ranged from 200 to $810 \mathrm{bp}$, with an average Q20 read length of $596 \mathrm{bp}$. All these BES have been deposited into the GenBank GSS database with consecutive accession numbers of [GenBank:FI857756-

Table I: A summary of BAC end sequences

\begin{tabular}{ll}
\hline Category & Numbers \\
\hline BAC sequence reactions & 84,480 \\
Total clean sequences & 63,387 (75\% success) \\
T7 sequences & 32,074 \\
SP6 sequences & 31,313 \\
Pair BAC end sequences & 25,676 \\
Total length sequenced & $37,784,877 \mathrm{bp}$ \\
Average length & $596 \mathrm{bp}$
\end{tabular}


FI900776]. A total of $37,784,877$ bp of genomic sequences was generated from this study, representing approximately $4 \%$ of the catfish genome. Analysis using the $37,784,877$ bp BES resulted in $11.91 \%$ of base pairs masked using the Danio repeat database, with the most abundant type of repeat being the DNA transposons. We previously reported the assessment of repetitive elements in the catfish genome and the additional 43,021 BES generated in this study confirmed our previous findings in general [25]. These BES [GenBank:DX083364DX103729] were also used for comparative genome analysis in this study.

\section{In silico analysis of the BAC-associated catfish genes on the zebrafish genome}

TBLASTX searches using the 63,387 catfish BES against the ENSEMBL zebrafish cDNA database with chromosome information resulted in 5,066 significant hits (Table 2). Of the 5,066 significant hits, 2,197 unique zebrafish genes were hit by a single BES while 1,024 unique zebrafish genes were hit by two or more catfish BES, making a total of 3,221 unique zebrafish genes with significant hits from the catfish BES. The 3,221 genes cover all 25 zebrafish chromosomes, with the largest number of gene hits being located on chromosome 5 (224 significant hits), followed by chromosome 7 (191 significant hits), chromosome 20 (171 significant hits), chromosome 6 (151 significant hits) and chromosome 19 (134 significant hits); and the smallest number of gene hits on chromosome 24 with 78 hits (Table 2). The number of gene hits on various chromosomes was approximately proportional to the sizes of the zebrafish chromosomes with some exceptions. When the size of chromosomes was taken into consideration, chromosome 25 had the largest number of gene hits with 3.5 hits per $\mathrm{Mb}$ or one hit per $286 \mathrm{~kb}$ on average, followed by chromosome 5, 4, 20, 19, and 22 with 3.2, 3.1, 3.0, 2.9, and 2.9 hits per $\mathrm{Mb}$, respectively (Table 2 ).

One particular finding of these BLAST searches is the observation of many highly repetitive genes. Out of 3,221 unique genes, 1,024 genes had hits from two or more BES. A single gene identity had hits from as many as 31 BES. A total of 14 genes had hits from at least 10 BES each (Table 3); an additional 139 genes had hits from 4-9 BES each;

Table 2: Distribution of comparatively anchored BAC clones using protein encoding gene sequences only.

\begin{tabular}{|c|c|c|c|c|c|c|c|c|}
\hline $\begin{array}{c}\text { Zebrafish } \\
\text { chromosome }\end{array}$ & $\begin{array}{l}\text { Chromosome } \\
\text { size (Mb) }\end{array}$ & $\begin{array}{l}\text { No. of } \\
\text { protein } \\
\text { encoding } \\
\text { genes* }\end{array}$ & $\begin{array}{l}\text { No. of } \\
\text { tBLASTx } \\
\text { hits }\end{array}$ & $\begin{array}{l}\text { Hits to } \\
\text { unique } \\
\text { genes }\end{array}$ & $\begin{array}{l}\text { Unique } \\
\text { gene hits } \\
\text { per Mb }\end{array}$ & $\begin{array}{c}\text { No. of } \\
\text { contigs with } \\
\text { single gene } \\
\text { hits }\end{array}$ & $\begin{array}{l}\text { No. of } \\
\text { contigs with } \\
\text { multiple } \\
\text { gene hits }\end{array}$ & $\begin{array}{c}\text { No. } \\
\text { putative } \\
\text { micro- } \\
\text { syntenies }\end{array}$ \\
\hline I & 56.2 & 818 & 205 & 123 & 1.83 & 75 & 17 & 13 \\
\hline 2 & 54.4 & 875 & 194 & 133 & 2.13 & 85 & 15 & 13 \\
\hline 3 & 62.9 & 975 & 196 & 127 & 1.75 & 72 & 18 & 13 \\
\hline 4 & 42.6 & 743 & 221 & 130 & 2.77 & 78 & 16 & 9 \\
\hline 5 & 70.4 & 1,173 & 340 & 224 & 2.74 & 103 & 35 & 21 \\
\hline 6 & 59.2 & 818 & 232 & $15 \mid$ & 2.31 & 85 & 22 & 18 \\
\hline 7 & 70.3 & 990 & 283 & 191 & 2.33 & 80 & 34 & 25 \\
\hline 8 & 56.5 & 864 & 196 & 128 & 1.93 & 65 & 22 & 14 \\
\hline 9 & 51.5 & 700 & 212 & 133 & 2.17 & 61 & 21 & 16 \\
\hline 10 & 42.4 & 670 & 150 & 87 & 1.72 & 51 & 12 & 9 \\
\hline II & 44.6 & 627 & 161 & 121 & 2.26 & 67 & 16 & 10 \\
\hline 12 & 47.5 & 636 & 177 & 114 & 2.21 & 72 & 14 & 7 \\
\hline 13 & 53.5 & 744 & 200 & 113 & 1.96 & 67 & 21 & 14 \\
\hline 14 & 56.5 & 701 & 197 & 113 & I.77 & 84 & II & 7 \\
\hline 15 & 46.6 & 688 & 177 & 125 & 2.25 & 68 & 14 & 8 \\
\hline 16 & 53.1 & 773 & 181 & 124 & 2.02 & 77 & 14 & 10 \\
\hline 17 & 52.3 & 715 & 180 & 115 & 1.99 & 62 & 19 & 13 \\
\hline 18 & 49.3 & 749 & 193 & 121 & 2.23 & 47 & 22 & 21 \\
\hline 19 & 46.2 & 780 & 233 & 134 & 2.58 & 86 & 21 & 16 \\
\hline 20 & 56.5 & 1,053 & 277 & $17 \mid$ & 2.48 & 76 & 30 & 19 \\
\hline 21 & 46.1 & 721 & 163 & 117 & 2.28 & 63 & 14 & 10 \\
\hline 22 & 39.0 & 959 & 178 & 113 & 2.59 & 50 & 19 & 16 \\
\hline 23 & 46.4 & 669 & 204 & $12 \mid$ & 2.24 & 68 & 18 & 13 \\
\hline 24 & 40.3 & 513 & 117 & 78 & I.7I & 47 & 8 & 7 \\
\hline 25 & 32.9 & 597 & 199 & 114 & 3.04 & 65 & 19 & 14 \\
\hline $\begin{array}{c}\text { Total/ } \\
\text { Average }\end{array}$ & I,277.2 & |9,55 | & 5,066 & 3,221 & 2.21 & I,754 & 472 & 336 \\
\hline
\end{tabular}

*: Annotated genes only from ENSEMBL. 
Table 3: Distribution of genes with hits from multiple BAC end sequences, with details provided for genes with 10 or more hits from BAC end sequences

\begin{tabular}{|c|c|c|c|c|}
\hline No. of Genes & Putative Identities & No of BES hits & Presence in Zebrafish genome & Potential explanation \\
\hline 1 & $\begin{array}{l}\text { Novel protein similar to DNA } \\
\text { polymerases }\end{array}$ & 31 & 28 & $\begin{array}{l}\text { Repetitive elements related to } \\
\text { retroelements }\end{array}$ \\
\hline I & Methionine aminopeptidase I & 22 & 2 & $\begin{array}{l}\text { Repetitive elements or multigene } \\
\text { family }\end{array}$ \\
\hline 1 & NOD3 protein-like & 18 & 63 & $\begin{array}{l}\text { Common domains shared by many } \\
\text { related proteins }\end{array}$ \\
\hline 1 & $\begin{array}{l}\text { Similar to tudor domain containing } \\
7, \text { hypothetical protein LOC } 393661\end{array}$ & 17 & 89 & $\begin{array}{l}\text { Repetitive elements or repetitive } \\
\text { genes }\end{array}$ \\
\hline 1 & Similar to porf2 & 16 & 81 & $\begin{array}{l}\text { Repetitive elements or multigene } \\
\text { family }\end{array}$ \\
\hline I & $\begin{array}{l}\text { Similar to general transcription } \\
\text { factor II-I repeat domain-containing } \\
\text { protein } 2 \mathrm{~A}\end{array}$ & 16 & 82 & $\begin{array}{l}\text { Repetitive elements or multigene } \\
\text { family }\end{array}$ \\
\hline I & $\begin{array}{l}\text { Similar to novel G protein-coupled } \\
\text { receptor }\end{array}$ & 13 & 92 & $\begin{array}{l}\text { Repetitive elements or multigene } \\
\text { family }\end{array}$ \\
\hline I & $\begin{array}{l}\text { Similar to serine/threonine-protein } \\
\text { kinase pim-3; }\end{array}$ & 11 & 85 & $\begin{array}{l}\text { Repetitive elements or multigene } \\
\text { family }\end{array}$ \\
\hline I & $\begin{array}{l}\text { Similar to novel protein from Danio } \\
\text { rerio; }\end{array}$ & 11 & 85 & $\begin{array}{l}\text { Repetitive elements or multigene } \\
\text { family }\end{array}$ \\
\hline 1 & Similar to Dynein heavy chain 6 & 11 & 20 & $\begin{array}{l}\text { Repetitive elements or multigene } \\
\text { family }\end{array}$ \\
\hline $\mathrm{I}$ & ORF2 [Mus musculus domesticus] & 10 & 91 & $\begin{array}{l}\text { Repetitive elements or multigene } \\
\text { family }\end{array}$ \\
\hline 1 & $\begin{array}{l}\text { PREDICTED: tubulin, alpha, } \\
\text { ubiquitous isoform } 8 \text { [Macaca } \\
\text { mulatta] }\end{array}$ & 10 & 16 & $\begin{array}{l}\text { Repetitive elements or multigene } \\
\text { family }\end{array}$ \\
\hline 1 & $\begin{array}{l}\text { PREDICTED: similar to vacuolar } \\
\text { protein sorting } 52 \text { [Danio rerio] }\end{array}$ & 10 & 69 & $\begin{array}{l}\text { Repetitive elements or multigene } \\
\text { family }\end{array}$ \\
\hline 1 & GF20795 [Drosophila ananassae] & 10 & 4 & $\begin{array}{l}\text { Repetitive elements or multigene } \\
\text { family }\end{array}$ \\
\hline 14 & & Subtotal & & \\
\hline 68 & & $5-9$ & & $\begin{array}{l}\text { Repetitive elements or multigene } \\
\text { family }\end{array}$ \\
\hline 71 & & 4 & & $\begin{array}{l}\text { Repetitive elements or multigene } \\
\text { family }\end{array}$ \\
\hline 139 & & Subtotal & & \\
\hline 230 & & 3 & & $\begin{array}{l}\text { Potentially duplicated gene } \\
\text { candidates }\end{array}$ \\
\hline 641 & & 2 & & $\begin{array}{l}\text { Potentially duplicated gene } \\
\text { candidates }\end{array}$ \\
\hline 1024 & & Total & & \\
\hline
\end{tabular}

230 genes had hits from 3 BES each, and 641 genes had hits from 2 BES each (Table 3). Some of the genes with hits from multiple BES may represent a whole array of related genes with similar functional domains. For instance, 18 BES hit NOD3-like gene of channel catfish, which was just recently characterized; NOD3 gene existed as a single copy gene in the catfish genome [45], and apparently the multiple BES contained many related genes harboring domains present within the NOD3 gene. Theoretically, a fraction of genes should have hits by more than one BES, simply because of the genome coverage of the $\mathrm{BAC}$ clones. We believe that overlapping (including identical) BAC clones does account for some of the observed hits of genes by more than one BES (data not shown), especially for those with 2-3 BES hits. However, the mathematical chances do not support multiple BES hits of a single gene unless the gene itself is repetitive in the catfish genome. Additional research is warranted to fully understand the nature of these genes/sequences in the catfish genome, but clearly many of these represent classes of repetitive gene families such as DNA polymerase gene that had hits from 31 BES.

\section{Establishing microsyntenies}

Among the teleost genomes with high sequence coverage, zebrafish is the most closely related species to catfish [46]. Our initial BLAST searches of the catfish BES against the genome of the T. nigroviridis generated many fewer signif- 
icant hits compared to those against the zebrafish genome. Therefore, we concentrated our comparative analysis efforts with the zebrafish genome in this study.

Conserved syntenies are most often established by comparing genome sequences of related species. However, the whole genome sequence is not yet available from catfish. In the absence of the whole genome sequence, we attempted to establish microsyntenies based on physical linkage of gene sequences. With the genome resources available in catfish, we have taken three approaches. First, if the genes were identified from both ends of a single BAC clone, they are physically linked with a distance of the BAC clone insert size. If the same two genes are found linked in the zebrafish genome in the same genome neighborhood, a microsynteny can then be established. These genes from mate-paired BES are physically linked with the average distances between them being the average insert size of the catfish BAC library, i.e., $161 \mathrm{~kb}$. From the 63,387 BES, a total of 25,676 mate-paired BES were identified. Of these, 760 mate-paired BES had significant BLASTN hits against the zebrafish genome sequence. However, only 194 of the 760 significant hit pairs were on the same zebrafish chromosome, allowing syntenic comparison. Further tBLASTX searches against the ENSEMBL zebrafish cDNA database allowed identification of 95 mate-paired BES with genes on both sides. The genomic locations of these 95 mate-paired genes were determined from the zebrafish genome sequence. Fifty pairs were found to be present in neighboring genomic locations within one million base pairs, while the other 45 were present in more distant locations $(>1 \mathrm{Mb}$ ) on the same chromosomes. The vast majority of the 50 mate-paired genes were found to be within $500 \mathrm{~kb}$ on the zebrafish genome sequence; only 2 of the 50 pairs had a distance of 500-920 kb (Table 4), suggesting conserved syntenies of the involved genes.

We previously reported the relatively high levels of local region conservation. For instance, many genes within the bordering mate-paired genes were well conserved among catfish, zebrafish, and Tetraodon, as determined by direct sequencing of the catfish BAC DNA using primers predicted from known genes in zebrafish or Tetraodon [40]. We did not extend this part of the study, but all known genomic information suggested high levels of local genome conservation.

In addition to the 50 microsyntenies, we attempted to determine if significant gene hits in the same catfish BAC contigs also fall on the same chromosome locations comparable to the contig sizes. As shown in Table 2, of the contigs with gene hits, 1,754 contigs had only one gene hit, while 472 contigs had two or more gene hits within each contig. Because the genes in the same contig are physically linked, their linkage in a comparable distance in the zebrafish genome would indicate a conserved synteny. As shown in Figure 1, 2, 3, 4 \&5, the vast majority of gene hits within the same contigs were found to be located on the same zebrafish chromosomes with comparable distances as estimated from the catfish BAC contigs. Using such an approach, a total of 336 conserved microsyntenies was identified (Table 2). Presence of multiple gene hits within large BAC contigs would allow identification of extended large conserved syntenic regions. Many of the microsyntenies were conserved with extended genomic distance to span over several million base pairs (Figure 1, 2, 3, 4 \&5, for additional details, see Additional file 1). For instance, large conserved syntenies were identified from chromosomes 12, 13, 14, 22, 23, 24, and 25 (Figure 1, 2, 3,4 \&5). In spite of the identification of some relatively large conserved syntenic regions, the vast majority of the identified syntenies were microsyntenies. Such highly segmented microsyntenies are not very useful for genomewide comparative analysis. However, if scaffolds can be established by determining the relationships among the microsyntenies, large-scale genome comparison should be possible. We, therefore, used two zebrafish chromosomes as the query to demonstrate if super scaffolds can be established. Chromosome 7, one of the chromosomes with the highest number of significant gene hits, and chromosome 13, one of the chromosomes with a large number of contigs having two or more hits (indicative of high level of syntenic conservation), were chosen for further analysis using genetic linkage mapping.

\section{Genetic mapping of BAC end-anchored microsatellites}

In order to extend the scope of conserved microsyntenies, microsyntenies identified on zebrafish chromosomes 7 and 13 were genetically mapped to determine their chromosomal locations in the catfish genome. There were 373 significant BLASTN hits to zebrafish chromosome 13 involving 178 unique catfish BAC contigs; and 505 significant hits to zebrafish chromosome 7 involving 314 unique catfish BAC contigs. We, therefore, first identified microsatellites from these involved catfish BAC contigs, and then mapped them to the linkage groups when the microsatellites were polymorphic in the resource family. A total of 548 pairs of microsatellite primers were tested, of which 296 from 188 contigs (the details of the polymorphic markers are shown in the Additional file 2) were polymorphic in the resource family. Further analysis using JoinMap 4.0 allowed mapping of 290 microsatellite markers, of which 161 microsatellites were from BES with significant similarity to zebrafish chromosome 7, and 129 microsatellites were from BES with significant similarity to zebrafish chromosome 13 .

Mapping of microsatellites from contigs with hits to zebrafish chromosome 13 allowed identification of a 
Table 4: Summary of 50 conserved syntenies identified by comparison of 95 mate-paired genes of channel catfish with genomic locations of those on the zebrafish draft genome sequence.

\begin{tabular}{|c|c|c|c|c|c|}
\hline $\begin{array}{l}\text { Catfish } \\
\text { BAC ID }\end{array}$ & SP6 hits & T7 hits & zebrafish Chr & Chr location (Mb) & $\begin{array}{l}\text { Distance } \\
\text { (bp) }\end{array}$ \\
\hline 035116 & [GenBank:NP 001038735] & [GenBank:XP 689|46] & 2 & 38.61 & 18,048 \\
\hline $063 \mathrm{LI} 6$ & [GenBank:NP 001012377] & [GenBank:NP 001092217] & 2 & 19.25 & 48,679 \\
\hline 026B05 & [GenBank:XP 001921249$]$ & [GenBank:CAl20867] & 3 & 31.82 & 4,418 \\
\hline $098 \mathrm{D} 05$ & [GenBank:CAIII873] & [GenBank:NP 001038462] & 4 & 1.82 & 301,470 \\
\hline $007 M 06$ & [GenBank:XP 001333162 ] & [GenBank:NP 57।I05] & 5 & 5.46 & 379,579 \\
\hline $028 \mathrm{M} 04$ & [GenBank:XP 687685] & [GenBank:NP 958867] & 5 & 22.23 & 133,063 \\
\hline 074L07 & [GenBank:XP 0013349|2] & [GenBank:XP 687570] & 5 & 15.69 & 290,598 \\
\hline $035 \mathrm{NII}$ & [GenBank:NP 001032187$]$ & [GenBank:NP 958882] & 6 & 18.25 & 231,524 \\
\hline 040]24 & [GenBank:XP 6866/3] & [GenBank:NP 991309] & 6 & 7.37 & 443,524 \\
\hline 077F04 & [GenBank:NP 001034906] & [GenBank:NP 001038813] & 6 & $1 \mathrm{l} .42$ & 484,877 \\
\hline $032 \mathrm{~F} 20$ & [GenBank:XP 69|291] & [GenBank:NP 001075I59] & 7 & 28.40 & 244,425 \\
\hline $062 \mathrm{~B} 16$ & [GenBank:NP 00100865I] & [GenBank:NP 001017550] & 7 & 15.05 & 222,416 \\
\hline $075 \mathrm{~K} 10$ & [GenBank:NP 956505] & [GenBank:NP 001070187] & 7 & 13.34 & 268,455 \\
\hline 103121 & [GenBank:NP 998033] & [GenBank:NP 001।59825] & 7 & 22.34 & 293,845 \\
\hline $047 \mathrm{~N} 13$ & [GenBank:XP 699919] & [GenBank:XP 699627] & 8 & 23.84 & 203,260 \\
\hline $057 N 22$ & [GenBank:XP 001923800] & [GenBank:NP 997066] & 9 & 36.69 & 163,677 \\
\hline $076 \mathrm{H} 22$ & [GenBank:NP 001004563] & [GenBank:XP 001921910$]$ & 9 & 13.84 & 313,352 \\
\hline $105 N 24$ & [GenBank:NP 001 I22018] & [GenBank:NP 997992.2] & 9 & 27.37 & 268,271 \\
\hline $056 \mathrm{~A} 23$ & [GenBank:NP 998295] & [GenBank:NP 001103164] & 10 & 7.50 & 486,745 \\
\hline $068 C 21$ & [GenBank:NP 001019272] & [GenBank:XP 001920077$]$ & 10 & 17.72 & 104,067 \\
\hline $093 \mathrm{~K} 02$ & [GenBank:XP 001344325] & [GenBank:XP 001919728$]$ & 10 & 41.67 & 152,479 \\
\hline $096 \mathrm{~A} / 4$ & [GenBank:NP 00I 120805] & [GenBank:NP 997775] & 11 & 10.02 & 980,276 \\
\hline OIOBI5 & [GenBank:NP 956715] & [GenBank:NP 956756] & 12 & 25.17 & 111,625 \\
\hline $04 \mid B 24$ & [GenBank:NP 001002607] & [GenBank:XP 693784] & 12 & 13.59 & 398,886 \\
\hline $109 K 22$ & [GenBank:XP 001920588] & [GenBank:XP 001920550$]$ & 12 & 25.55 & 449,096 \\
\hline $018 \mathrm{HII}$ & [GenBank:NP 9569|5] & [GenBank:NP 997743] & 13 & 23.23 & 293,181 \\
\hline $026 C 08$ & [GenBank:NP 001119869 ] & [GenBank:NP 95661I] & 13 & 23.50 & 201,663 \\
\hline 027E09 & [GenBank:XP 001922173 ] & [GenBank:XP 001921791$]$ & 14 & 0.22 & 574,761 \\
\hline $103 F 19$ & [GenBank:NP 57|477] & [GenBank:XP 001919973$]$ & 14 & 22.90 & 256,143 \\
\hline 022D09 & [GenBank:NP 001096112] & [GenBank:XP 68442I] & 15 & 29.14 & 418,219 \\
\hline 059B20 & [GenBank:XP 682817] & [GenBank:XP 691794] & 15 & 27.80 & 94,396 \\
\hline 077H08 & [GenBank:XP 001920240] & [GenBank:NP 001070609] & 15 & 6.05 & 339,215 \\
\hline 004003 & [GenBank:NP 001020707] & [GenBank:NP 001020642] & 16 & 10.40 & 149,618 \\
\hline 075M09 & [GenBank:NP 001107266] & [GenBank:NP 001082899] & 16 & 8.30 & 120,355 \\
\hline 104108 & [GenBank:NP 57187I] & [GenBank:NP 694503] & 16 & 27.17 & 214,517 \\
\hline $013 \mathrm{P} 16$ & [GenBank:NP 001076304] & [GenBank:NP 001038173] & 18 & 18.65 & 366,849 \\
\hline $042 \mathrm{~J} 20$ & [GenBank:NP 001037796] & [GenBank:NP 00I038370] & 18 & 32.85 & 223,781 \\
\hline 02 ILI3 & [GenBank:NP 001038343] & [GenBank:XP 68891I] & 19 & 17.40 & 286,019 \\
\hline $052 \mathrm{~N} 18$ & [GenBank:XP 001921158 ] & [GenBank:NP 956134] & 19 & 7.59 & 345,553 \\
\hline 056A09 & [GenBank:NP 001018463] & [GenBank:NP 0010384I6] & 19 & 13.46 & 122,217 \\
\hline $065 \mathrm{M} 02$ & [GenBank:XP 001922809] & [GenBank:NP 001038686] & 19 & 15.37 & 430,325 \\
\hline 080021 & [GenBank:NP 956277] & [GenBank:NP 57/262] & 19 & 17.06 & 389,643 \\
\hline $086 \mathrm{Cl} 6$ & [GenBank:XP 0013409/2] & [GenBank:NP 001038562] & 19 & 6.00 & 364,590 \\
\hline $\mathrm{OIOH} 22$ & [GenBank:NP 998602] & [GenBank:XP 001920851$]$ & 21 & 2.24 & 240,019 \\
\hline 034114 & [GenBank:NP 001038838] & [GenBank:NP 956334] & 21 & 20.16 & 306,102 \\
\hline $081 \mathrm{IJ} 0$ & [GenBank:NP 0010024II] & [GenBank:NP 001073439 ] & 21 & 22.12 & 277,818 \\
\hline $099 \mathrm{H} 22$ & [GenBank:NP 001076277] & [GenBank:XP 699221] & 22 & 7.03 & II 5,754 \\
\hline 053PII & [GenBank:NP 001002173 ] & [GenBank:NP 001035|37] & 23 & 30.73 & 197,703 \\
\hline 068010 & [GenBank:XP 001339131$]$ & [GenBank:XP 689922] & 23 & 18.01 & 332,973 \\
\hline $105 \mathrm{HIO}$ & [GenBank:NP 001103636] & [GenBank:NP 001098596] & 23 & 33.36 & 274,318 \\
\hline Average & & & & & 278,648 \\
\hline
\end{tabular}

highly conserved chromosome between catfish and zebrafish. As shown in Figure 6, of the 129 microsatellites from BES with high similarities to the zebrafish chromosome 13, 57 microsatellites from 43 contigs were mapped into a single linkage group, spanning approximately 90 centi-Morgans, suggesting the conservation of a large segment of this chromosome. However, the entire chromosome is not conserved. The 129 microsatellites were 


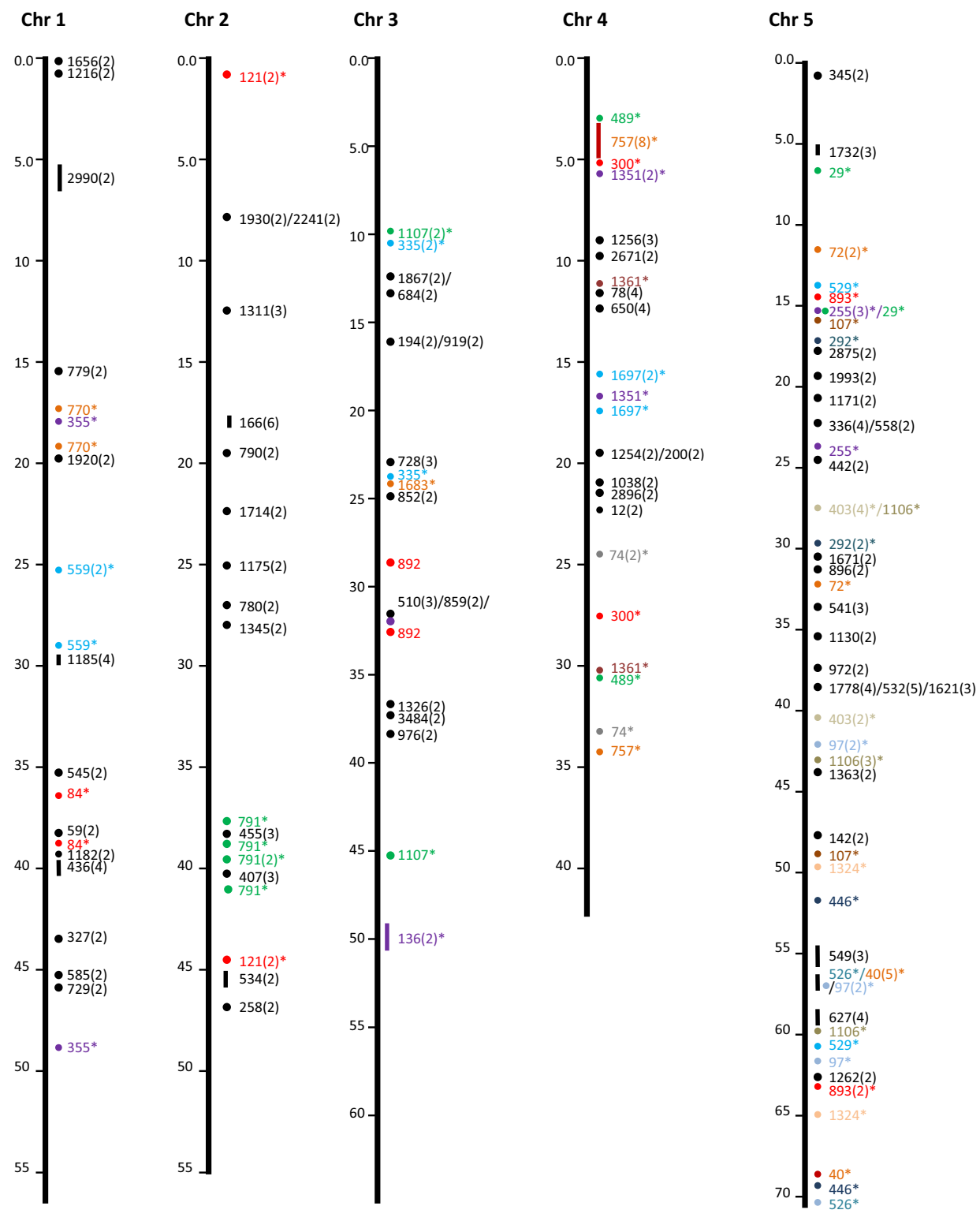

Figure I

Identification of microsyntenies through comparative sequence analysis (chr I through chr 5). tBLASTX searches were conducted using BAC contig-associated BAC end sequences as queries against the zebrafish genome sequence. The putative conserved microsyntenies are presented along the 25 zebrafish chromosomes (chr I through chr 25). The position of the zebrafish sequence is shown on the left of each chromosome bars in million base pairs. The conserved microsyntenies are indicated on the right side of the chromosome bars, with the numbers representing the contig numbers of the BAC assembly of the catfish physical map [4I]. Circles represent short syntenic regions and short vertical lines represent relatively longer conserved syntenic regions proportional to the length of the bar with a number in parenthesis representing the number of conserved sequences within the microsyntenies. The microsyntenies designated with asterisks $(*)$ are those with duplicated conservation of the microsyntenies that are color-coded to facilitate the visualization of the duplicated syntenic regions along the chromosome. Duplicated syntenic regions refer to a conserved genomic segment between the catfish genome and the zebrafish genome that is duplicated in the zebrafish genome such that identical or nearly identical significant hits are generated from two chromosomal regions of the zebrafish genome using a single catfish genome segment (say it is a contig or a scaffold) as the query. In just few cases, this term is used in an extended fashion to include those that are tripled in the zebrafish genome. 


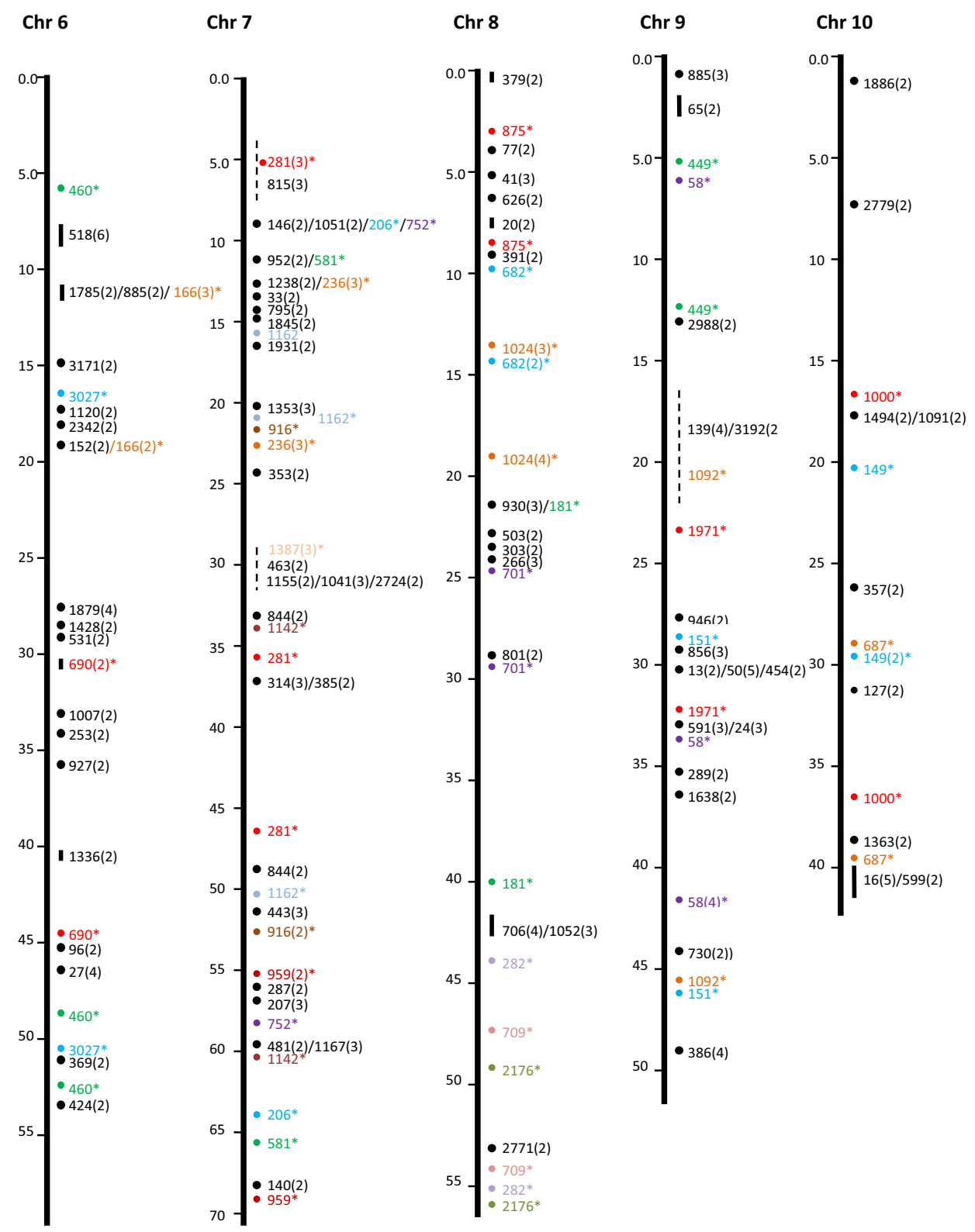

\section{Figure 2}

Identification of microsyntenies through comparative sequence analysis (chr 6 through chr 10). tBLASTX searches were conducted using BAC contig-associated BAC end sequences as queries against the zebrafish genome sequence. The putative conserved microsyntenies are presented along the 25 zebrafish chromosomes (chr I through chr 25). The position of the zebrafish sequence is shown on the left of each chromosome bars in million base pairs. The conserved microsyntenies are indicated on the right side of the chromosome bars, with the numbers representing the contig numbers of the BAC assembly of the catfish physical map [4I]. Circles represent short syntenic regions and short vertical lines represent relatively longer conserved syntenic regions proportional to the length of the bar with a number in parenthesis representing the number of conserved sequences within the microsyntenies. The microsyntenies designated with asterisks $(*)$ are those with duplicated conservation of the microsyntenies that are color-coded to facilitate the visualization of the duplicated syntenic regions along the chromosome. Duplicated syntenic regions refer to a conserved genomic segment between the catfish genome and the zebrafish genome that is duplicated in the zebrafish genome such that identical or nearly identical significant hits are generated from two chromosomal regions of the zebrafish genome using a single catfish genome segment (say it is a contig or a scaffold) as the query. In just few cases, this term is used in an extended fashion to include those that are tripled in the zebrafish genome. 
mapped to a total of 24 linkage groups, with seven of the 24 linkage groups containing 4-12 markers (see Additional file 2).

Similarly but to a much lesser extent, microsatellites from BES with similarities to the zebrafish chromosome 7 were mapped to three major linkage groups (Figure 7). Once again, many smaller syntenic regions were mapped to various linkage groups, suggesting high levels of local conservation and low levels of chromosomal conservation. Nonetheless, the significant aspect of this is that scaffolds can be established by linking various contigs together through linkage mapping. This will allow integration of genetic linkage and physical maps once microsatellites are identified from most contigs of the physical map. Such scaffolds should guide genome sequence assembly in the future, and should also provide molecular length measurements of various polymorphic markers along the genome of catfish, providing guidance for the development of the SNP chip technology in catfish. Apparently, SNP chips constructed from evenly distributed SNPs provide the best coverage of the catfish genome when conducting the whole genome association studies.

Genetic linkage mapping of BAC end-anchored microsatellites provided a level of validation of the physical map. Discrepancies were found between the BAC assemblage and the linkage map. Of the 75 contigs with at least 2 markers, 54 contigs were mapped properly into the same linkage groups. However, 18 contigs were mapped into different linkage groups (see Additional file 2). Of these 18 contigs, 12 are large contigs with at least 40 BACs. Apparently, such discrepancy is indicative of mistakes in the BAC assemblage. Mapping additional BAC endanchored microsatellites is under way to integrate the genetic linkage and physical maps, and to correct any additional mistakes in the assembly of the physical map [42].

\section{Conclusion}

Some highly conserved chromosomes or chromosomal regions exist between catfish and zebrafish. High levels of local conservation were found, but a high level of chromosomal shuffling and rearrangements exists between catfish and zebrafish genomes. Comparative genome analysis using zebrafish genome sequence is highly useful for regional comparisons, but not so useful at the chromosomal levels. The significance of comparative genome analysis in catfish is that it will allow more cost-effective structural genomic analysis, but more importantly, orthologues established through comparative genome analysis should facilitate functional assignment of genes. Given that functional genomics is more difficult with nonmodel fish species, inference from orthologues should be one of the most efficient and reliable approaches for functional analysis of the catfish genome.
Overall, the evolutionary syntenic conservation appeared to be relatively low between the catfish genome and the genomes of the zebrafish. This indicates many chromosome breakage and rearrangements among the fish genomes occurred during evolution. These findings are consistent with our previous findings that high levels of conservation were found within small genomic regions, whereas high levels of large-scale genome reshuffling were evident when comparing the genomes of catfish and zebrafish $[26,40]$. These conclusions, however, are based on the assumption that the zebrafish genome assembly is correct. Apparently, due to the assembly mistakes in the zebrafish genome, some of the syntenic breaks may be due to the still poor assembly of the zebrafish genome. We also acknowledge that comparative genome analysis using a partial bank of sequences in catfish and a more complete databank in zebrafish could potentially lead to a bias. Caution should be exercised when establishing concrete syntenic relations. Such limitations themselves justify the need for whole genome sequencing in catfish.

\section{Methods \\ $B A C$ culture and $B A C$-end sequencing}

The CHORI-212 Channel Catfish BAC library [47] was used for BAC-end sequencing. BAC culture and sequencing reactions were conducted using standard protocols, and as previously described $[25,40]$. Briefly, BAC clones were transferred from 384-well plates to 96-well culture blocks containing $1.5 \mathrm{ml}$ of $2 \times$ YT medium with $12.5 \mu \mathrm{g} /$ $\mathrm{ml}$ chloramphenicol and grown at $37^{\circ} \mathrm{C}$ overnight with shaking at $300 \mathrm{rpm}$. The blocks were centrifuged at 2000 $\times \mathrm{g}$ for $10 \mathrm{~min}$ in an Eppendorf 5804R bench top centrifuge to collect bacteria. The culture supernatant was decanted and the blocks were inverted and tapped gently on paper towels to remove remaining liquid. BAC DNA was isolated using the Perfectprep ${ }^{\mathrm{TM}}$ BAC 96 kit (Eppendorf, Westbury, NY) according to the manufacturer's specifications. BAC DNA was collected in 96-well plates and stored at $-20^{\circ} \mathrm{C}$ until usage.

Sequencing of channel catfish BAC ends was conducted using the BigDye ${ }^{\circledast}$ Terminator v3.1 Cycle Sequencing Kit (Applied Biosystems, Foster City, CA), with modifications. Each sequencing reaction mix contained $2 \mu \mathrm{l}$ of $5 \times$ sequencing buffer, $2 \mu \mathrm{l}$ of primer $(3 \mathrm{pmol} / \mu \mathrm{l}), 1.5 \mu \mathrm{l}$ BigDye v3.1 dye terminator, and $4.5 \mu$ of BAC DNA. BAC clones were sequenced from both ends using the primers T7 (5'-TAATACGACTCACTATAGGG-3') and SP6 (5'-ATTTAGGTGACACTATAG-3'). Cycle sequencing was carried out in 96-well plate format using PTC-200 thermal cyclers (MJ Research/Bio-Rad, Hercules, CA) under the following thermal profile: an initial denaturing at $95^{\circ} \mathrm{C}$ for $5 \mathrm{~min}$, followed by 100 cycles of $95^{\circ} \mathrm{C}$ for $30 \mathrm{~s}, 53^{\circ} \mathrm{C}$ for $10 \mathrm{~s}$, and $60^{\circ} \mathrm{C}$ for $4 \mathrm{~min}$. Products were purified using ethanol/EDTA precipitation according to the BigDye protocol (Applied Biosystems), with the following modifications. 


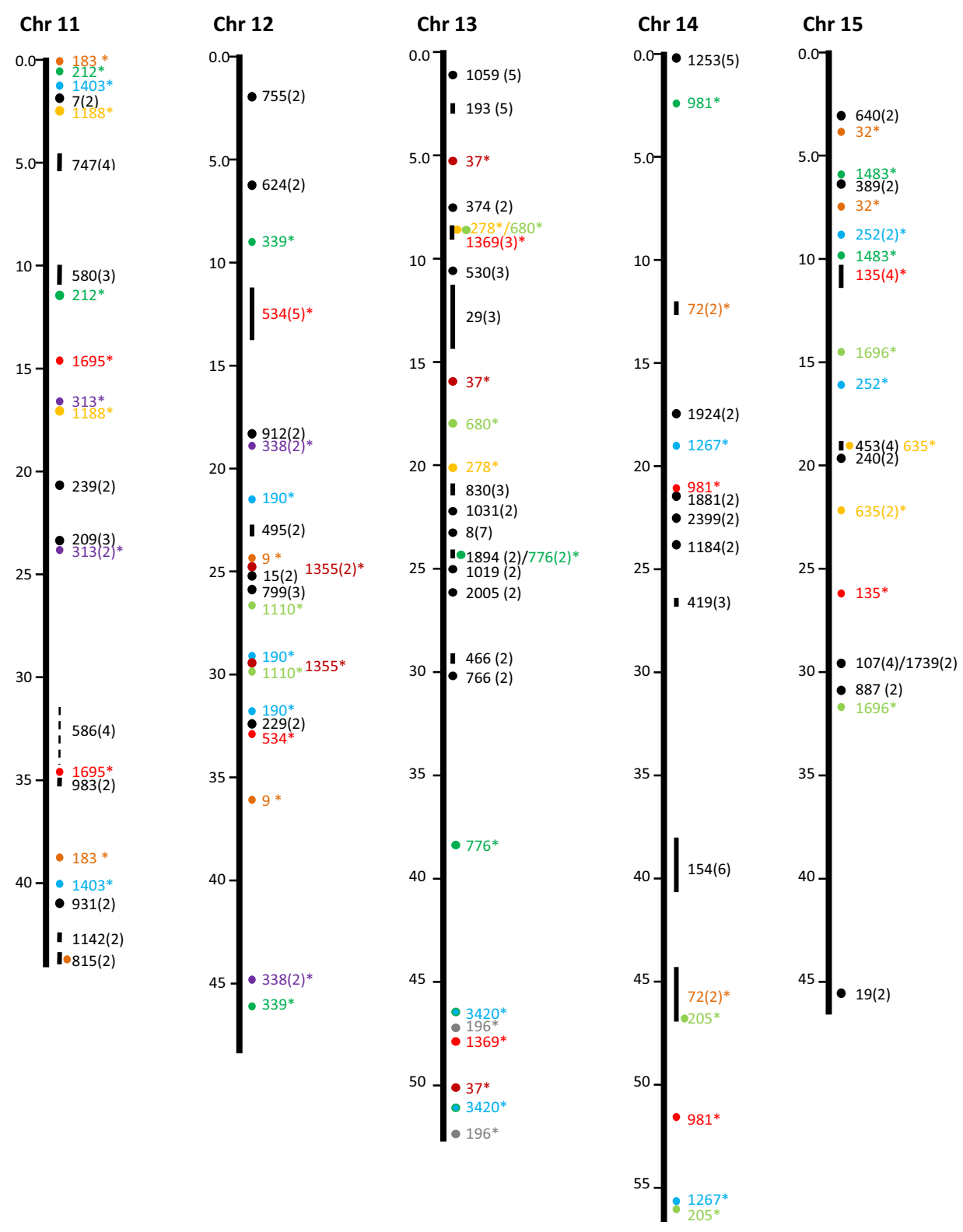

Figure 3

Identification of microsyntenies through comparative sequence analysis (chr I I through chr I5). tBLASTX

searches were conducted using BAC contig-associated BAC end sequences as queries against the zebrafish genome sequence. The putative conserved microsyntenies are presented along the 25 zebrafish chromosomes (chr I through chr 25). The position of the zebrafish sequence is shown on the left of each chromosome bars in million base pairs. The conserved microsyntenies are indicated on the right side of the chromosome bars, with the numbers representing the contig numbers of the BAC assembly of the catfish physical map [4I]. Circles represent short syntenic regions and short vertical lines represent relatively longer conserved syntenic regions proportional to the length of the bar with a number in parenthesis representing the number of conserved sequences within the microsyntenies. The microsyntenies designated with asterisks $(*)$ are those with duplicated conservation of the microsyntenies that are color-coded to facilitate the visualization of the duplicated syntenic regions along the chromosome. Duplicated syntenic regions refer to a conserved genomic segment between the catfish genome and the zebrafish genome that is duplicated in the zebrafish genome such that identical or nearly identical significant hits are generated from two chromosomal regions of the zebrafish genome using a single catfish genome segment (say it is a contig or a scaffold) as the query. In just few cases, this term is used in an extended fashion to include those that are tripled in the zebrafish genome. 


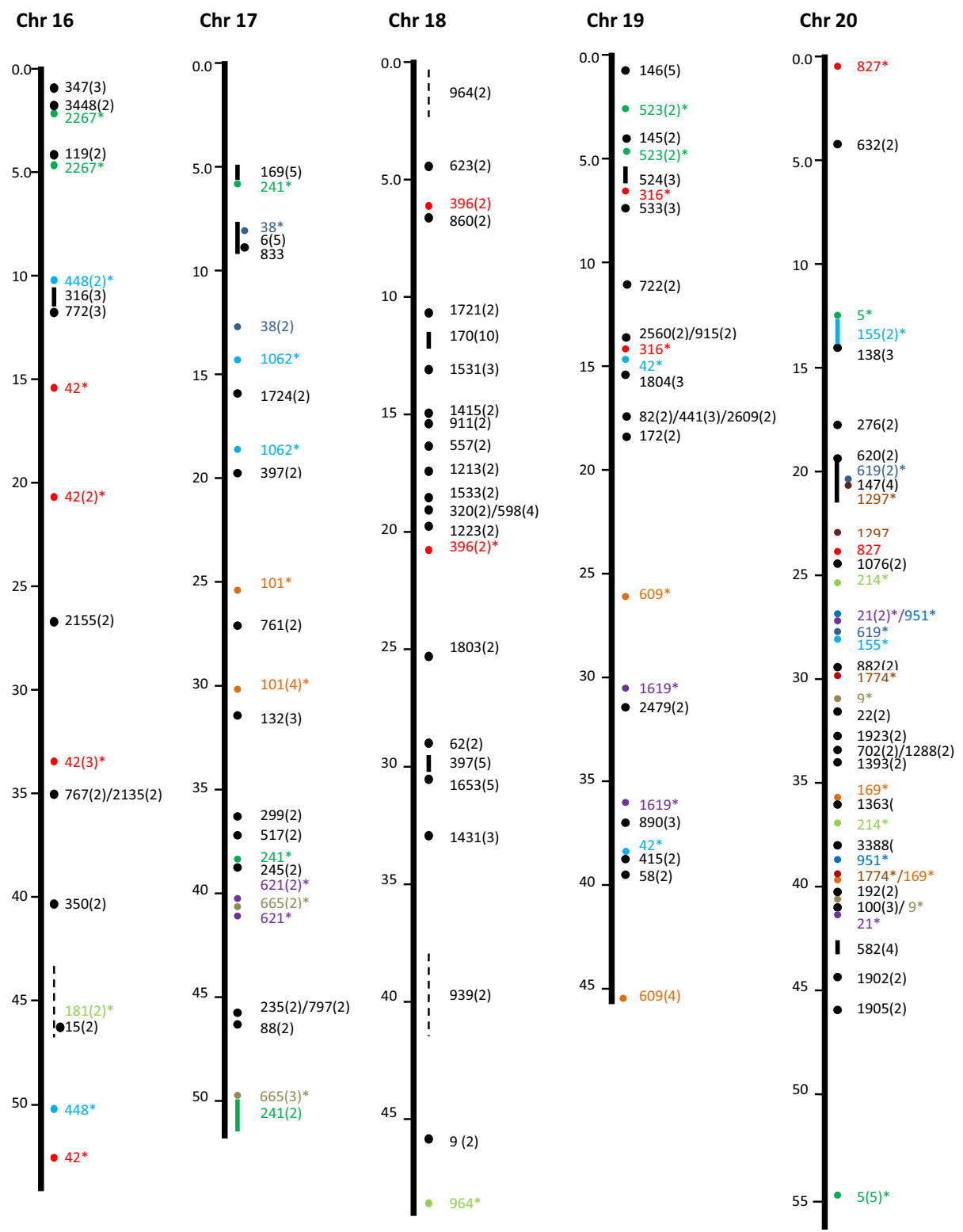

\section{Figure 4}

Identification of microsyntenies through comparative sequence analysis (chr 16 through chr 20). tBLASTX

searches were conducted using BAC contig-associated BAC end sequences as queries against the zebrafish genome sequence. The putative conserved microsyntenies are presented along the 25 zebrafish chromosomes (chr I through chr 25). The position of the zebrafish sequence is shown on the left of each chromosome bars in million base pairs. The conserved microsyntenies are indicated on the right side of the chromosome bars, with the numbers representing the contig numbers of the BAC assembly of the catfish physical map [4I]. Circles represent short syntenic regions and short vertical lines represent relatively longer conserved syntenic regions proportional to the length of the bar with a number in parenthesis representing the number of conserved sequences within the microsyntenies. The microsyntenies designated with asterisks $(*)$ are those with duplicated conservation of the microsyntenies that are color-coded to facilitate the visualization of the duplicated syntenic regions along the chromosome. Duplicated syntenic regions refer to a conserved genomic segment between the catfish genome and the zebrafish genome that is duplicated in the zebrafish genome such that identical or nearly identical significant hits are generated from two chromosomal regions of the zebrafish genome using a single catfish genome segment (say it is a contig or a scaffold) as the query. In just few cases, this term is used in an extended fashion to include those that are tripled in the zebrafish genome. 

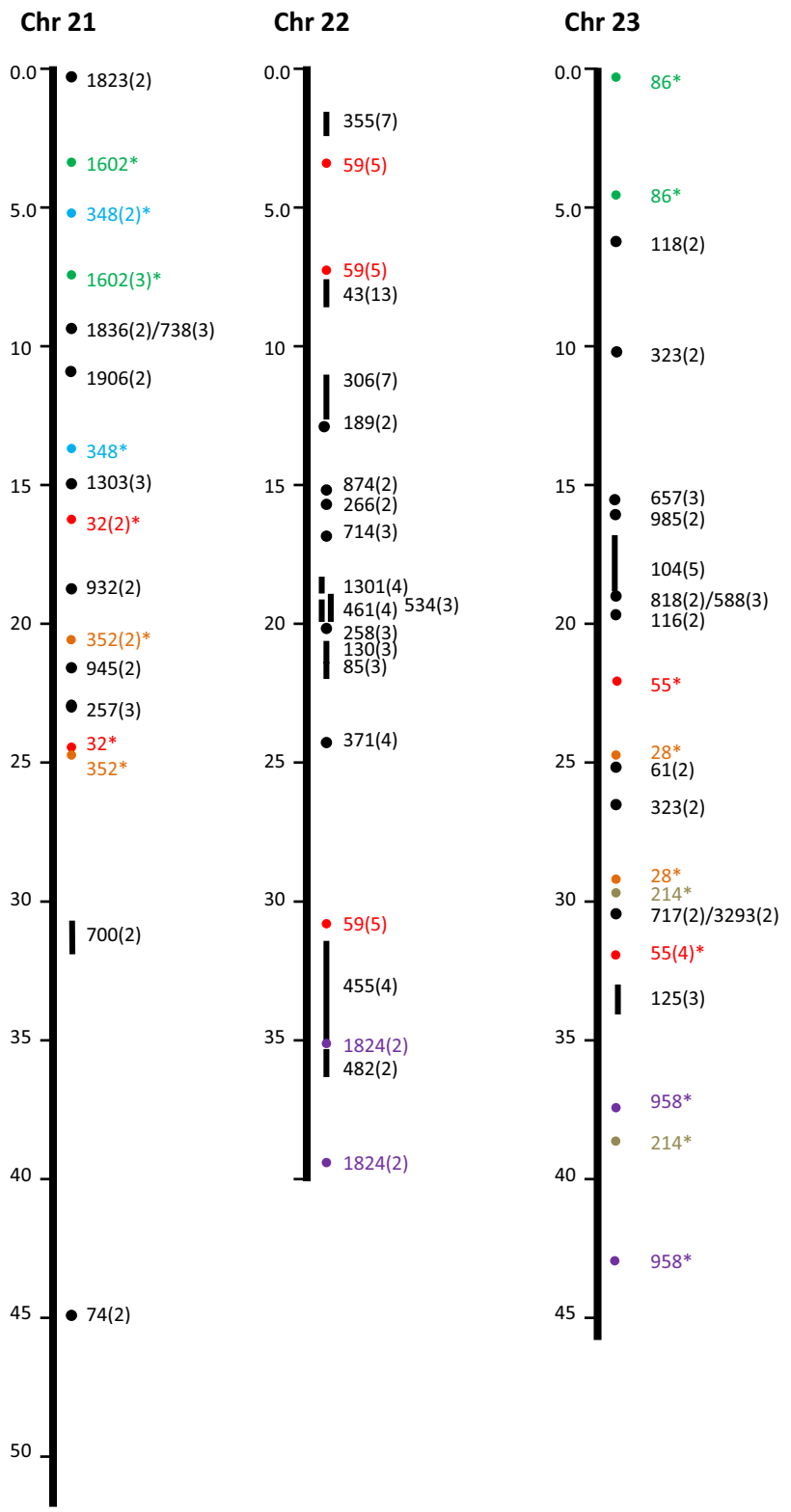

Chr 24
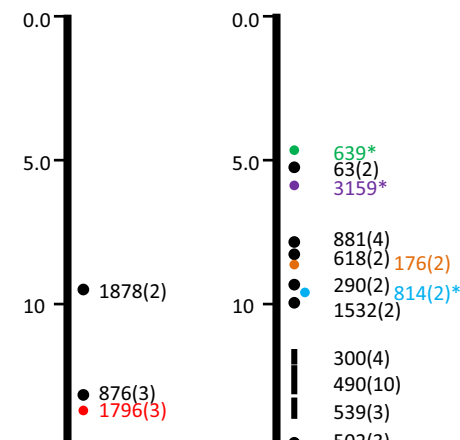

$10-\bullet \quad 290(2)$

$300(4)$

$\prod \begin{aligned} & 490(10) \\ & 539(3)\end{aligned}$

$15-\bullet \quad 502(3)$

$15-\quad 502(3)$

$20-\begin{aligned} & 1796(3) \\ & 1293(2) \\ & 759(2)\end{aligned}$

$20-$ I $564(3)$

I $3515(2)$

- 569*

25

- $814(2)^{*}$

224(3)

30

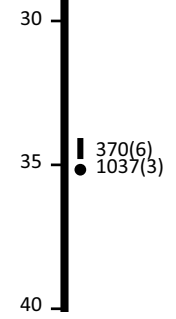

- $1084(2)$

\section{Figure 5}

Identification of microsyntenies through comparative sequence analysis (chr 2 I through chr 25). tBLASTX

searches were conducted using BAC contig-associated BAC end sequences as queries against the zebrafish genome sequence. The putative conserved microsyntenies are presented along the 25 zebrafish chromosomes (chr I through chr 25). The position of the zebrafish sequence is shown on the left of each chromosome bars in million base pairs. The conserved microsyntenies are indicated on the right side of the chromosome bars, with the numbers representing the contig numbers of the BAC assembly of the catfish physical map [4I]. Circles represent short syntenic regions and short vertical lines represent relatively longer conserved syntenic regions proportional to the length of the bar with a number in parenthesis representing the number of conserved sequences within the microsyntenies. The microsyntenies designated with asterisks $(*)$ are those with duplicated conservation of the microsyntenies that are color-coded to facilitate the visualization of the duplicated syntenic regions along the chromosome. Duplicated syntenic regions refer to a conserved genomic segment between the catfish genome and the zebrafish genome that is duplicated in the zebrafish genome such that identical or nearly identical significant hits are generated from two chromosomal regions of the zebrafish genome using a single catfish genome segment (say it is a contig or a scaffold) as the query. In just few cases, this term is used in an extended fashion to include those that are tripled in the zebrafish genome. 


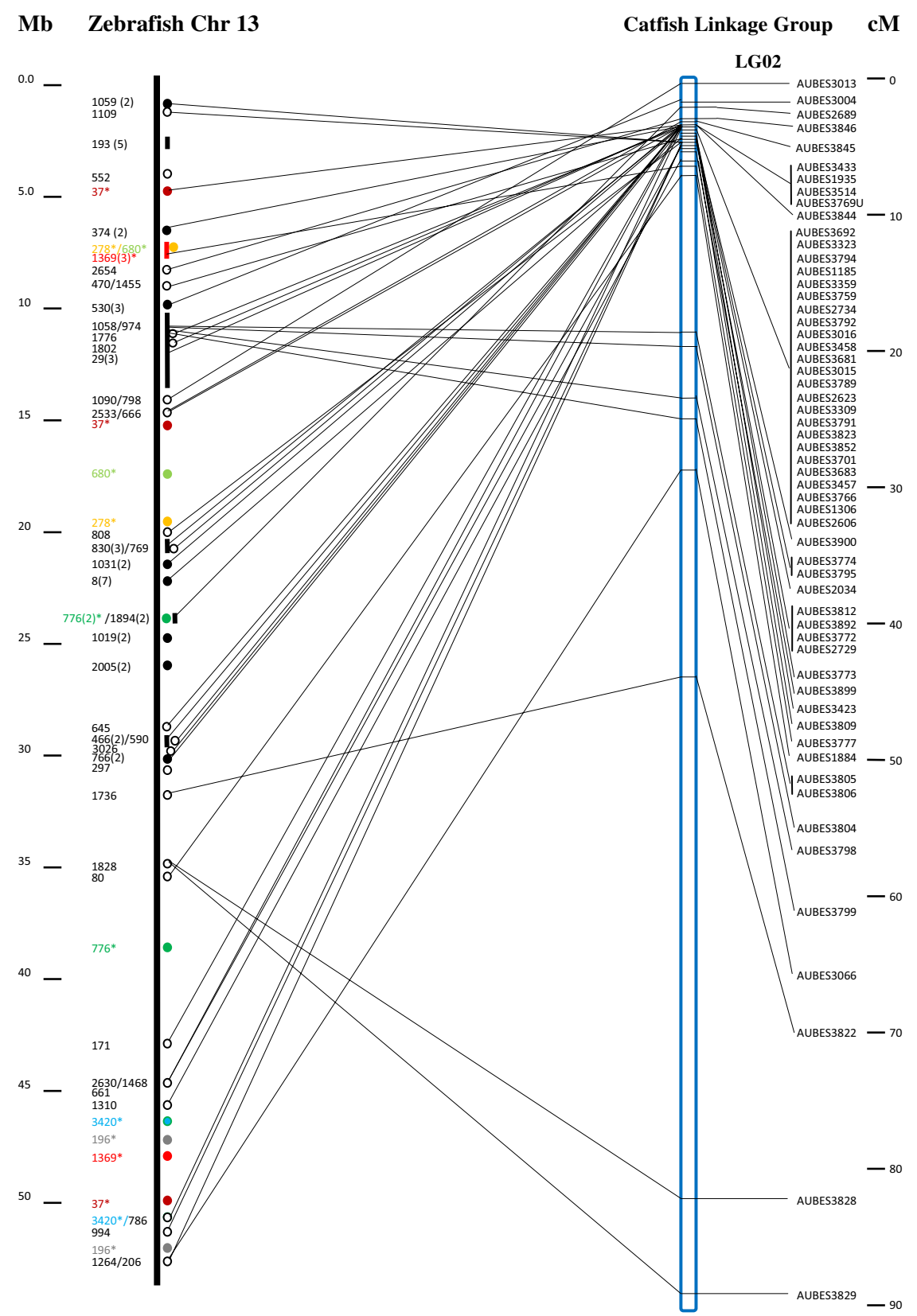

\section{Figure 6}

Scaffolds of conserved syntenic regions between the catfish and zebrafish genomes. Scaffolds of conserved syntenic regions were established by genetic linkage mapping of BAC contig-associated microsatellites. The zebrafish chromosome 13 (chr I3) is presented with its base positions on the far left in million base pairs; The second column of the numbers are catfish BAC contig numbers [4I], with the identified syntenic regions shown immediately right of the chromosome bar. The numbers in the parenthesis are the number of conserved sequences; the circles and bars represent relatively short and long conserved syntenic regions; the asterisks represent duplicated syntenic regions with color coding to facilitate the visualization of duplicated regions, the same way as described under Figure I legend, except that the open circles represent conserved sequences coming from non-gene sequences while the solid circles represent conserved gene sequences. Microsatellites from the BAC contigs were genetically mapped to linkage groups as shown on the right, with the names of microsatellites being labeled on the second most right, e.g., AUBES I884. The positional relationship of the conserved syntenies on the zebrafish genome sequence and within the catfish linkage group is indicated by thin lines linking the zebrafish chromosome and the catfish linkage group positions. The positions of markers within the linkage group are shown on the furthest right in centi-Morgans. 


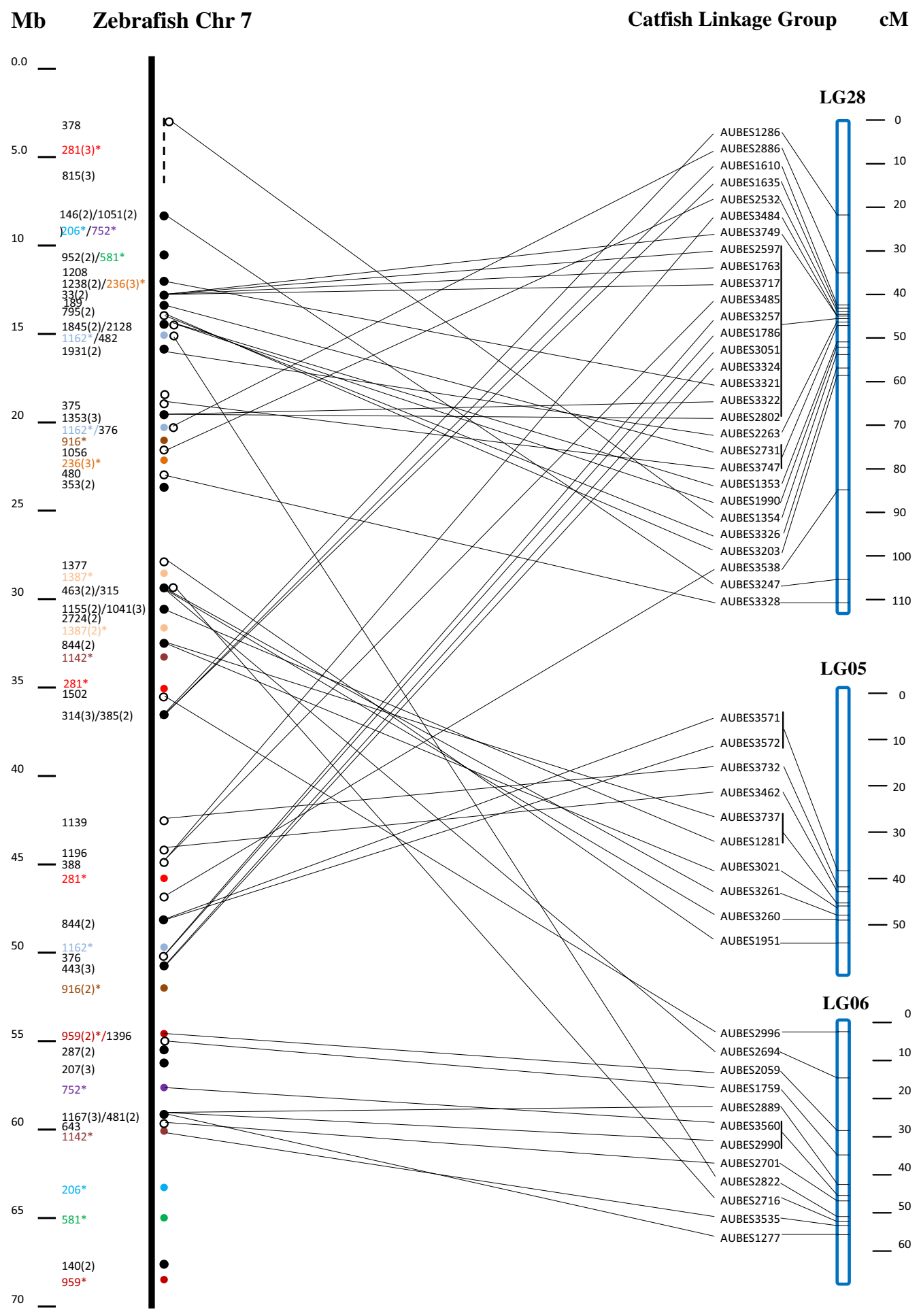

\section{Figure 7}

Scaffolds of conserved syntenic regions between the catfish linkage groups and zebrafish chromosome 7.

Details of the methods used for the identification and presentation of the syntenic regions are the same as described under Figure 6. 
After thermal cycling, $1 \mu \mathrm{l}$ of $125 \mathrm{mM}$ EDTA and $30 \mu \mathrm{l}$ chilled $\left(-80^{\circ} \mathrm{C}\right) 100 \%$ ethanol were added to each reaction. Plates were gently mixed and incubated at room temperature for $15 \mathrm{~min}$. Plates were then centrifuged at 2,250 $\times \mathrm{g}$ at $4^{\circ} \mathrm{C}$ for $30 \mathrm{~min}$, followed by washing in $30 \mu \mathrm{l}$ of $70 \%$ ethanol at $2,000 \times \mathrm{g}$ for $15 \mathrm{~min}$. Ethanol was decanted and $8 \mu \mathrm{l} \mathrm{Hi-Di}{ }^{\mathrm{TM}}$ formamide (Applied Biosystems) was added to each well to re-suspend DNA. Products were denatured at $95^{\circ} \mathrm{C}$ for $5 \mathrm{~min}$ and sequenced on a 3130xl genetic analyzer (Applied Biosystems).

\section{Sequence processing and analysis}

The raw BES base calling were conducted by using Phred $[48,49]$ with Q20 as a cut-off. Lucy program [50] was used to remove the vector sequences and short sequence less than 200 bp. Repeats were masked using REPEATMASKER [51] before BLAST analysis. In order to anchor the catfish BES to the zebrafish genome, TBLASTX searches of the repeat-masked BES were conducted against the ENSEMBLE zebrafish cDNA database (Assembly 7).

\section{Identification of conserved syntenies between catfish and zebrafish}

In the absence of the whole genome sequence, we attempted to establish microsyntenies based on physical linkage of gene sequences. First, if the genes were identified from both sides of a single BAC clone (mate-paired $\mathrm{BES}$ ), then they are physically linked with a distance of the BAC clone insert size. If the same two genes were found to be linked on the zebrafish genome in the same genome neighborhood, a microsynteny was established.

Initially, BES were analyzed by BLASTN ( $E$-value $\leq-5)$ for the identification of mate-pairs with significant hits on both sides of the BAC insert. Mate-paired BES were analyzed by tBLASTX (E-value $\leq-5)$ for the identification of genes on both sides of the BAC insert. After identification, the two mate-paired genes in each BAC were used as queries to search for their chromosomal locations on the zebrafish genome. Conserved microsyntenies were declared when the mate-paired genes existed within a distance of $1.0 \mathrm{Mb}$ within the zebrafish genome.

Syntenies were also established using genes within contiguous sequences (contigs) based on the catfish physical map [42]. Genes identified from BES were located along the catfish physical map. Genes identified within the same contig and located on the same zebrafish chromosome with comparable distances as estimated from the catfish BAC contig, an extended synteny was established.

\section{Construction of the catfish syntenic groups using linkagemaps}

In order to assess the scope of microsyntenies, two zebrafish chromosomes, chromosome 7 and 13, were chosen for analysis. Chromosome 7 had the largest number of significant hits and chromosome 13 had a large number of contigs having two or more hits (suggestive of high level of syntenic conservation). Syntenies were established using microsatellite-based linkage mapping. A total of 548 microsatellite loci in the contigs which had significant BLASTN hits to the zebrafish chromosome 7 and 13 were tested using a hybrid catfish resource family, $\mathrm{F}_{1}$-2 (female blue-channel catfish hybrid) $\times$ Ch-6 (male channel catfish) with 64 progeny.

Microsatellites were identified and analyzed using Msatfinder [52] and Vector NTI 10.0 (Invitrogen, Carlsbad, CA) as we previously described [24]. Polymerase chain reaction (PCR) primers were designed using Msatfinder [52]. Mononucleotide repeats were manually excluded. PCR amplification was conducted as previously described [24]. Briefly, each microsatellite PCR reaction contained $1 \times$ PCR buffer, $2 \mathrm{mM} \mathrm{MgCl}_{2}, 0.2 \mathrm{mM}$ of each dNTP, $4 \mathrm{ng}$ upper primer, 6 ng lower primer, 1 pmol labeled primer, and $0.25 \mathrm{U}$ of JumpStart Taq polymerase (Sigma, St. Louis, MO), and $20 \mathrm{ng}$ genomic DNA. PCR amplification was carried out using a touchdown program with the following thermal profile: an initial denaturation at $94^{\circ} \mathrm{C}$ for $3.5 \mathrm{~min}$, followed by $94^{\circ} \mathrm{C}$ for $30 \mathrm{~s}, 57^{\circ} \mathrm{C}$ for $30 \mathrm{~s}$, and $72^{\circ} \mathrm{C}$ for $30 \mathrm{~s}$ for 20 cycles as the first step, and at $94^{\circ} \mathrm{C}$ for $30 \mathrm{~s}, 53^{\circ} \mathrm{C}$ for $30 \mathrm{~s}$, and $72^{\circ} \mathrm{C}$ for $30 \mathrm{~s}$ for 15 cycles as the second step. A final extension was performed at $72^{\circ} \mathrm{C}$ for 10 minutes. The PCR products were analyzed on $7 \%$ sequencing gels using the 4300 DNA Analyzer (LI-COR ${ }^{\circledR}$ Biosciences, Lincoln, NE). After gel electrophoresis, loci were manually genotyped to determine allele segregation patterns and polymorphisms in the resource family.

The catfish linkage map was constructed using JoinMap version 4.0 software as we previously described [26] using the cross-pollinating (CP) coding scheme, which handles the data containing various genotype configurations with unknown linkage phases [53]. Linkage between markers was examined by estimating LOD scores for recombination rate, and map distances were calculated using the Kosambi mapping function. Significance of marker linkage was determined at a final LOD threshold of 3.0.

\section{Accession numbers}

The BES generated from this study have been deposited in GenBank and were assigned accession numbers from [GenBank:FI857756] to [GenBank:FI900776] and the existing BES from [GenBank:DX083364] to [GenBank:DX103729] were also used for comparative genome analysis in this study.

\section{Authors' contributions}

HL and YJ contributed equally and their contribution accounts for the major part of this study. SW and JA par- 
ticipated in data analysis and manuscript preparation. PN and BS assisted in developing microsatellite markers. PX assisted in culturing the BAC clone and extracted DNA. HK contributed major part in linkage mapping analysis. ZL supervised the entire study and prepared the manuscript. All authors read and approved the final manuscript.

\section{Additional material}

\section{Additional file 1}

tBLASTX search results. A portion of the tBLASTX search results used for the identification of microsyntenies. Query ID are sequence identification of catfish BAC end sequences used as queries; Subject ID is the identification of the sequence with significant tBLASTX hits at the E-values (E-values are coded in this Table. For instance, 0.29 means $e^{-29}, 0.06$ means $e^{-}$ $\left.{ }^{6}\right)$. Chromosome number is provided in the column Chr, with starting position (Chr SS) and ending position (Chr SE) provided. The potential gene identities are detailed under Description.

Click here for file

[http://www.biomedcentral.com/content/supplementary/14712164-10-592-S1.XLS]

\section{Additional file 2}

Primers used to map the BAC end associated microsatellites. Ctg_ID is contig number on the catfish physical map; Contig size refers to the number of BAC clones within the contig; BAC_ID is BAC identification number; Upper and lower primer sequences, and the linkage groups the microsatellites were mapped are given in column $E, F$, and $G$, respectively. Click here for file

[http://www.biomedcentral.com/content/supplementary/14712164-10-592-S2.XLS]

\section{Acknowledgements}

This project was supported by grants from USDA NRI Animal Genome Tools and Resources Program (USDA/NRICGP award\# 2009-3520505I0I, and partially award \#2006-356 16-16685).

\section{References}

I. Fujiyama A, Watanabe H, Toyoda A, Taylor TD, Itoh T, Tsai S-F, Park H-S, Yaspo M-L, Lehrach H, Chen Z, Fu G, Saitou N, Osoegawa K, de Jong PJ, Suto Y, Hattori M, Sakaki Y: Construction and Analysis of a Human-Chimpanzee Comparative Clone Map. Science 2002, 295:|3|-|34.

2. Gregory SG, Sekhon M, Schein J, Zhao S, Osoegawa K, Scott CE, Evans RS, Burridge PW, Cox TV, Fox CA, Hutton RD, Mullenger IR, Phillips KJ, Smith J, Stalker J, Threadgold GJ, Birney E, Wylie K, Chinwalla A, Wallis J, Hillier L, Carter J, Gaige T, Jaeger S, Kremitzki C, Layman D, Maas J, McGrane R, Mead K, Walker R, Jones S, Smith M, Asano J, Bosdet I, Chan S, Chittaranjan S, Chiu R, Fjell C, Fuhrmann D, Girn N, Gray C, Guin R, Hsiao L, Krzywinski M, Kutsche R, Lee SS, Mathewson C, McLeavy C, Messervier S, Ness S, Pandoh P, Prabhu AL, Saeedi P, Smailus D, Spence L, Stott J, Taylor S, Terpstra W, Tsai M, Vardy J, Wye N, Yang G, Shatsman S, Ayodeji B, Geer K, Tsegaye G, Shvartsbeyn A, Gebregeorgis E, Krol M, Russell D, Overton L, Malek JA, Holmes M, Heaney M, Shetty J, Feldblyum T, Nierman WC, Catanese JJ, Hubbard T, Waterston RH, Rogers J, de Jong PJ, Fraser CM, Marra M, McPherson JD, Bentley DR: A physical map of the mouse genome. Nature 2002, 41 8:743-750.

3. Larkin DM, Wind A Everts-van der, Rebeiz M, Schweitzer PA, Bachman S, Green C, Wright CL, Campos EJ, Benson LD, Edwards J, Liu L, Osoegawa K, Womack JE, de Jong PJ, Lewin HA: A cattle-human comparative map built with cattle BAC-ends and human genome sequence. Genome Res 2003, 13:1966-1972.

4. Leeb T, Vogl C, Zhu B, de Jong PJ, Binns MM, Chowdhary BP, Scharfe M, Jarek M, Nordsiek G, Schrader F, Bloker H: A human-horse comparative map based on equine BAC end sequences. Genomics 2006, 87:772-776.

5. Meyers SN, Rogatcheva MB, Larkin DM, Yerle M, Milan D, Hawken RJ, Schook LB, Beever JE: Piggy-BACing the human genome: II. A high-resolution, physically anchored, comparative map of the porcine autosomes. Genomics 2005, 86:739-752.

6. Dalrymple BP, Kirkness EF, Nefedov M, McWilliam S, Ratnakumar A, Barris W, Zhao S, Shetty J, Maddox JF, O'Grady M, Nicholas F, Crawford AM, Smith T, de Jong PJ, McEwan J, Oddy VH, Cockett NE: Using comparative genomics to reorder the human genome sequence into a virtual sheep genome. Genome Biol 2007, 8:RI52.

7. Moen T, Hayes B, Baranski M, Berg PR, Kjoglum S, Koop BF, Davidson WS, Omholt SW, Lien S: A linkage map of the Atlantic salmon (Salmo salar) based on EST-derived SNP markers. BMC Genomics 2008, 9:223.

8. Ng SHS, Artieri CG, Bosdet IE, Chiu R, Danzmann RG, Davidson WS, Ferguson MM, Fjell CD, Hoyheim B, Jones SJM, de Jong PJ, Koop BF, Krzywinski MI, Lubieniecki K, Marra MA, Mitchell LA, Mathewson C, Osoegawa K, Parisotto SE, Phillips RB, Rise ML, von Schalburg KR, Schein JE, Shin H, Siddiqui A, Thorsen J, Wye N, Yang G, Zhu B: A physical map of the genome of Atlantic salmon, Salmo salar. Genomics 2005, 86:396-404.

9. Rise ML, von Schalburg KR, Brown GD, Mawer MA, Devlin RH, Kuipers N, Busby M, Beetz-Sargent M, Alberto R, Gibbs AR, Hunt P, Shukin R, Zeznik JA, Nelson C, Jones SR, Smailus DE, Jones SJ, Schein JE, Marra MA, Butterfield YS, Stott JM, Ng SH, Davidson WS, Koop BF: Development and application of a salmonid EST database and CDNA microarray: data mining and interspecific hybridization characteristics. Genome Res 2004, 14:478-490.

10. Guyomard R, Mauger S, Tabet-Canale K, Martineau S, Genet C, Krieg F, Quillet E: A type I and type II microsatellite linkage map of rainbow trout (Oncorhynchus mykiss) with presumptive coverage of all chromosome arms. BMC Genomics 2006, 7:302.

11. Rexroad CE, Lee Y, Keele JW, Karamycheva S, Brown G, Koop B, Gahr SA, Palti Y, Quackenbush J: Sequence analysis of a rainbow trout cDNA library and creation of a gene index. Cytogenet Genome Res 2003, 102:347-354.

12. Katagiri T, Kidd C, Tomasino E, Davis JT, Wishon C, Stern JE, Carleton KL, Howe AE, Kocher TD: A BAC-based physical map of the Nile tilapia genome. BMC Genomics 2005, 6:89.

13. Lee BY, Lee WJ, Streelman JT, Carleton KL, Howe AE, Hulata G, Slet$\tan A$, Stern JE, Terai Y, Kocher TD: A second-generation genetic linkage map of tilapia (Oreochromis spp.). Genetics 2005, 170:237-244.

14. Franch R, Louro B, Tsalavouta M, Chatziplis D, Tsigenopoulos CS, Sarropoulou E, Antonello J, Magoulas A, Mylonas CC, Babbucci M, Patarnello T, Power DM, Kotoulas G, Bargelloni L: A genetic linkage map of the hermaphrodite teleost fish Sparus aurata $L$. Genetics 2006, 174:85I-86I.

15. Sarropoulou E, Power DM, Magoulas A, Geisler R, Kotoulas G: Comparative analysis and characterization of expressed sequence tags in gilthead sea bream (Sparus aurata) liver and embryos. Aquaculture 2005, 243:69-8I.

16. Sarropoulou E, Franch R, Louro B, Power DM, Bargelloni L, Magoulas A, Senger F, Tsalavouta M, Patarnello T, Galibert F, Kotoulas G, Geisler R: A gene-based radiation hybrid map of the gilthead sea bream Sparus aurata refines and exploits conserved synteny with Tetraodon nigroviridis. BMC Genomics 2007, 8:44.

17. Senger F, Priat C, Hitte C, Sarropoulou E, Franch R, Geisler R, Bargelloni L, Power D, Galibert F: The first radiation hybrid map of a perch-like fish: The gilthead seabream (Sparus aurata L). Genomics 2006, 87:793-800.

18. Chistiakov DA, Hellemans B, Haley CS, Law AS, Tsigenopoulos CS, Kotoulas G, Bertotto D, Libertini A, Volckaert FA: A microsatellite linkage map of the European sea bass Dicentrarchus labrax $L$. Genetics 2005, 170:1821-1826.

19. Whitaker HA, McAndrew BJ, Taggart JB: Construction and characterization of a BAC library for the European sea bass Dicentrarchus labrax. Anim Genet 2006, 37:526.

20. Liu Z: A review of catfish genomics: progress and perspectives. Comp Funct Genomics 2003, 4:259-265. 
21. Liu Z: Catfish. In Genome Mapping and Genomics in Fishes and Aquatic Animals Volume 2. Edited by: Kocher T, Kole C. Berlin Heidelberg: Springer; 2008:85-100. [Kole C (Series Editor): Genome Mapping and Genomics in Animals, vol. 2]

22. He C, Chen L, Simmons M, Li P, Kim S, Liu ZJ: Putative SNP discovery in interspecific hybrids of catfish by comparative EST analysis. Anim Genet 2003, 34:445-448.

23. Serapion J, Kucuktas H, Feng J, Liu Z: Bioinformatic mining of type I microsatellites from expressed sequence tags of channel catfish (Ictalurus punctatus). Mar Biotechnol (NY) 2004, 6:364-377.

24. Somridhivej B, Wang S, Sha Z, Liu H, Quilang J, Xu P, Li P, Hu Z, Liu $Z$ : Characterization, polymorphism assessment, and database construction for microsatellites from BAC end sequences of channel catfish (Ictalurus punctatus): A resource for integration of linkage and physical maps. Aquaculture 2008, 275:76-80.

25. Xu P, Wang S, Liu L, Peatman E, Somridhivej B, Thimmapuram J, Gong $G$, Liu Z: Channel catfish BAC-end sequences for marker development and assessment of syntenic conservation with other fish species. Anim Genet 2006, 37:321-326.

26. Kucuktas H, Wang S, Li P, He C, Xu P, Sha Z, Liu H, Jiang Y, Baoprasertkul P, Somridhivej B, Wang Y, Abernathy J, Guo X, Liu L, Muir W, Liu Z: Construction of Genetic Linkage Maps and Comparative Genome Analysis of Catfish Using Gene-associated Markers. Genetics 2009, I 8 I: I649- I660.

27. Liu Z, Karsi A, Li P, Cao D, Dunham R: An AFLP-based genetic linkage map of channel catfish (Ictalurus punctatus) constructed by using an interspecific hybrid resource family. Genetics 2003, 165:687-694.

28. Waldbieser GC, Bosworth BG, Nonneman DJ, Wolters WR: A microsatellite-based genetic linkage map for channel catfish, Ictalurus punctatus. Genetics 200I, I 58:727-734.

29. Cao D, Kocabas A, Ju Z, Karsi A, Li P, Patterson A, Liu Z: Transcriptome of channel catfish (Ictalurus punctatus): initial analysis of genes and expression profiles of the head kidney. Anim Genet 2001, 32:169-188.

30. Ju Z, Karsi A, Kocabas A, Patterson A, Li P, Cao D, Dunham R, Liu Z: Transcriptome analysis of channel catfish (Ictalurus punctatus): genes and expression profile from the brain. Gene 2000, 261:373-382.

31. Karsi A, Cao D, Li P, Patterson A, Kocabas A, Feng J, Ju Z, Mickett KD, Liu Z: Transcriptome analysis of channel catfish (Ictalurus punctatus): initial analysis of gene expression and microsatellite-containing cDNAs in the skin. Gene 2002, 285:157-168.

32. Kocabas AM, Li P, Cao D, Karsi A, He C, Patterson A, Ju Z, Dunham RA, Liu Z: Expression profile of the channel catfish spleen: analysis of genes involved in immune functions. Mar Biotechnol (NY) 2002, 4:526-536.

33. Li P, Peatman E, Wang S, Feng J, He C, Baoprasertkul P, Xu P, Kucuktas H, Nandi S, Somridhivej B, Serapion J, Simmons M, Turan C, Liu L, Muir W, Dunham R, Brady Y, Grizzle J, Liu Z: Towards the ictalurid catfish transcriptome: generation and analysis of 31,215 catfish ESTs. BMC Genomics 2007, 8: 177.

34. Ju Z, Dunham RA, Liu Z: Differential gene expression in the brain of channel catfish (Ictalurus punctatus) in response to cold acclimation. Mol Genet Genomics 2002, 268:87-95.

35. Li RW, Waldbieser GC: Production and utilization of a highdensity oligonucleotide microarray in channel catfish, Ictalurus punctatus. BMC Genomics 2006, 7:134.

36. Liu Z, Li RW, Waldbieser GC: Utilization of microarray technology for functional genomics in ictalurid catfish. J Fish Biol 2008 , 72:2377-2390.

37. Peatman E, Baoprasertkul P, Terhune J, Xu P, Nandi S, Kucuktas H, Li P, Wang S, Somridhivej B, Dunham R, Liu Z: Expression analysis of the acute phase response in channel catfish (Ictalurus punctatus) after infection with a Gram-negative bacterium. Dev Comp Immunol 2007, 3 I: I I83-I I96.

38. Peatman E, Terhune J, Baoprasertkul P, Xu P, Nandi S, Wang S, Somridhivej $B$, Kucuktas $H$, Li $P$, Dunham $R$, Liu Z: Microarray analysis of gene expression in the blue catfish liver reveals early activation of the MHC class I pathway after infection with Edwardsiella ictaluri. Mol Immunol 2008, 45:553-566.

39. Quiniou SM, Katagiri T, Miller NW, Wilson M, Wolters WR, Waldbieser GC: Construction and characterization of a BAC library from a gynogenetic channel catfish Ictalurus punctatus. Genet Sel Evol 2003, 35:673-683.

40. Wang S, Xu P, Thorsen J, Zhu B, de Jong PJ, Waldbieser G, Kucuktas $\mathrm{H}$, Liu Z: Characterization of a BAC library from channel catfish Ictalurus punctatus: indications of high levels of chromosomal reshuffling among teleost genomes. Mar Biotechnol (NY) 2007, 9:70I-7II.

4I. Quiniou SM, Waldbieser GC, Duke MV: A first generation BACbased physical map of the channel catfish genome. $B M C$ Genomics 2007, 8:40.

42. Xu P, Wang S, Liu L, Thorsen J, Kucuktas H, Liu Z: A BAC-based physical map of the channel catfish genome. Genomics 2007 , 90:380-388.

43. Nandi S, Peatman E, Xu P, Wang S, Li P, Liu Z: Repeat structure of the catfish genome: a genomic and transcriptomic assessment of Tcl-like transposon elements in channel catfish (Ictalurus punctatus). Genetica 2007, I 3 I:8 I-90.

44. Sarropoulou E, Nousdili D, Magoulas A, Kotoulas G: Linking the genomes of nonmodel teleosts through comparative genomics. Mar Biotechnol (NY) 2008, 10:227-233.

45. Sha Z, Abernathy WJ, Wang S, Li P, Kucuktas H, Liu H, Peatman E, Liu $Z$ : NOD-like subfamily of the nucleotide-binding domain and leucine-rich repeat containing family receptors and their expression in channel catfish. Dev Comp Immunol 2009, 31:991-999.

46. Steinke D, Salzburger W, Meyer A: Novel relationships among ten fish model species revealed based on a phylogenomic analysis using ESTs. J Mol Evol 2006, 62:772-784.

47. CHORI-212: Channel Catfish (Ictalurus punctatus) BAC Library [http://bacpac.chori.org/library.php?id=103]

48. Ewing B, Green P: Base-calling of automated sequencer traces using phred. II. Error probabilities. Genome Res 1998, 8: $186-194$.

49. Ewing B, Hillier L, WendI MC, Green P: Base-calling of automated sequencer traces using phred. I. Accuracy assessment. Genome Res 1998, 8:175-185.

50. Chou $\mathrm{HH}$, Holmes $\mathrm{MH}$ : DNA sequence quality trimming and vector removal. Bioinformatics 2001, I 7:1093-I I04.

5I. RepeatMasker Open-3.0 [http://www.repeatmasker.org]

52. Msatfinder: detection and characterisation of microsatellites [http://www.genomics.ceh.ac.uk/msatfinder/]

53. Sekino M, Kobayashi T, Hara M: Segregation and linkage analysis of 75 novel microsatellite DNA markers in pair crosses of Japanese abalone (Haliotis discus hannai) using the 5'-tailed primer method. Mar Biotechnol (NY) 2006, 8:453-466.

\section{Publish with Bio Med Central and every scientist can read your work free of charge}

"BioMed Central will be the most significant development for disseminating the results of biomedical research in our lifetime. "

Sir Paul Nurse, Cancer Research UK

Your research papers will be:

- available free of charge to the entire biomedical community

- peer reviewed and published immediately upon acceptance

- cited in PubMed and archived on PubMed Central

- yours - you keep the copyright
BioMedcentral 